\title{
Prepositional Errors in the Writings of Pakistani ESL Students
}

\author{
Abdul Saeed ${ }^{1}$, Sajid Hussain ${ }^{2} \&$ Surhan Fatima $^{1}$ \\ ${ }^{1}$ Sukkur Institute of Business Administration, Sukkur, Pakistan \\ ${ }^{2}$ Karakoram International University, Gilgit-Baltistan, Pakistan \\ Correspondence: Abdul Saeed, Sukkur Institute of Busniess Administration, Airport Road, Sukkur, Pakistan. Tel: \\ 92-0321-310-6812.E-mail: saeedabdulskr@gmail.com
}

Received: March 9, 2015 Accepted: April 14, $2015 \quad$ Online Published: May 30, 2015

doi:10.5539/ijel.v5n3p120 URL: http://dx.doi.org/10.5539/ijel.v5n3p120

\begin{abstract}
Today, English has emerged as an important means of communication across the world including Pakistan. In Pakistan, it enjoys the status of second language as it is offered as a compulsory subject from primary level up to higher classes. In addition, there is great need and demand for having a sound grasp over English language to encounter professional challenges. However, Pakistani learners still face various problems while speaking and writing English. This study examined the abuse of English prepositions by Pakistani learners. It focused on the types of prepositional errors found in their English writing. Moreover, the study investigated whether male learners committed more preposition errors or female. For this purpose, twenty six (26) students of HSSC (thirteen participants from each gender) were chosen through systematic random sampling under Quantitative research paradigm. The data were collected through composition test and essay writing which were then analyzed through tables and graphics. Consequently, the study found out various types of prepositional errors in the participants' writing. Besides, the study showed higher ratio of errors in female participants' writing than the males'. At the end of the study, some recommendations were given as how to lessen the ratio of English preposition errors in Pakistani learners' writing.
\end{abstract}

Keywords: error analysis, prepositional error, gender analysis

\section{Introduction}

Language is the most powerful source of communication and self-expression through which we express our feelings, emotions and share ideas (Saeed, 1998). Through language, we can also receive as well as transmit knowledge to other people. Most of the activities in the world are carried out through or by it. Talking about languages, we cannot ignore English, which is widely and rapidly spreading over the horizon of the present world. As a result of it, English cannot be kept limited to dialects. Rather many varieties have been explored and added. In this regard, Kuchru (1992) designed a model in which English has been classified into three circles i.e., inner circle, outer circle and expanding circle. This model is comprised of dialects and varieties. According to it, Pakistani English is counted in outer circle because it is considered as second language in our education system. In addition, English is taught in Pakistan from primary level to high levels. The Student who is proficient in English language is deemed to be intelligent with high status and prestige. It is the reason that English as an international language is used in all professions like education, business, medicine and media. So, the students who are not good at English are considered to be less genius and intelligent. That is why, in Pakistan, there is a great need and demand for having a sound grasp over English language. As a result it is observed that every person tries to speak English even though he may commit errors and mistakes in the areas of grammar, spelling, structure, pronunciation etc. However, it is noticed that mostly students commit errors in English grammar i.e. written and spoken forms (Rehman, 2008).

While talking about grammar, both of its categories need to be discussed. They are; (a) Primary category and (b) secondary category. The former one consists of parts of speech including nouns, pronouns, verbs, adjectives, adverbs, prepositions, articles and conjunctions whereas the (b) is comprised of tense, person and gender. However, in this study, we have focused only prepositions and the errors that ESL learners commit while using preposition in English (L2) writing. The examination of literature reveals that syntax and practice of a language are essential factors for grasping of a language including English (Swan, 2003). The above discussion leads to comment that the structure of language can be understood only by understanding the components of language. To draft valid and 
correct English, a student needs to know what, when, where and how to use the components of the language. But when we see the Pakistani student's drafting, we can observe various types of mistakes and errors related to nouns, pronouns, verbs, adverbs, and conjunctions in general and prepositions in particular (Rehman, 2006). These errors may be due to the variation and differences between the natures of mother tongue (L1) and the target language's (TL) writings. A learner may perform better in his/her mother tongue with least hesitation and with a few possibilities of errors than in English writing. For such situation, various social, cultural, linguistic and cognitive factors may be considered responsible which create hurdle for Pakistani ESL learners' English writing. Keeping these differences in mind, Silva (1993) claimed second and foreign language writing tend to be more constrained, difficult and less effective than writing in a first language.

\subsection{Statement of the Problem}

English Language as earlier mentioned has gained a status of second language in Pakistan, taught as a compulsory subject from primary to higher level but the problems and challenges faced by the students have not been solved as they observantly commit various sorts of errors including prepositional errors particularly. Gardner (1985) holds the view that the social and cultural milieus in which learners grow up determine their attitudes and motivational orientation towards the target language. In Pakistani society, to a great extent, male and female enjoy different status. They have different opportunities for learning that affect their process of learning Second Language. Besides, individual differences cannot be ignored in the process of learning second language. Griffith (1991), differentiated males being 'Field Independence' to perform well in formal setting while females being 'Field Dependent' to perform well in informal setting. Larson-Freeman and Lang (1991) put 'Field Independence and Field Dependence" on fourth standard in individual differences. Lakoff (1975) claims that women's language is very close to the standard language as compare to men's. The present study is an attempt to investigate performance of both male and female by conducting a comparative study of L2 writing at HSSC level with following questions.

\subsection{Research Questions}

Who commits more prepositional errors i.e. male or female ESL learners?

\subsection{Research Hypothesis}

Male students commit more prepositional errors than the female students.

\subsection{Significance of the Study}

As this research work has a focus on the incorrect usages of prepositions in written language, it may be beneficial for English teachers to set up strategies as how to enable the students to overcome these problems. Moreover, the study may make the teacher realise to modify the existing teaching strategies and techniques according to the needs of the students. Besides, this study may make the students conscious of the wrong usages of prepositions. This identification process will make them realize to root these errors out of their English writings.

\subsection{Literature Review}

In the field of linguistics, the term error has been used differently; some uses it in terms of breaching of code (Corder, 1967) while the other means it a "deviation from the norms of the target language (Ellis, 1994, p. 51). Here, it is essential to mention that this deviation may be phonological, syntactic and morphological from the standard code of target language (Long, 1977), which are not accepted by the teacher due to its "inappropriateness in the real life discourse" (Hendrickson, 1980, p.169). But whatsoever it means, it is believed that errors help us in the process of learning if due attention is paid. Errors help in realizing the gap found between the learners' existing and the desired levels of knowledge. However, if errors are not rooted out, it defames the learners' knowledge and creates hurdles in their learning process. It may be one of the reasons that errors particularly linguistic errors have been focused by researchers and linguists and consequently identified its different types i.e., inter-lingual and intra-lingual errors, induced errors, overt and covert errors, global and local errors and expressive and receptive errors.

Inter-lingual errors occur due to the interference of L1 into L2. They are considered to be very important in the learning of L2 as Brown (2000) writes "Interlingua transfer is a significant source of error for all learners. The beginning stages of learning a second language are especially unassailable to inter-lingual transfer from the native language or interference (p. 224)." Intra-lingual errors are those errors that occur due to the faulty or partial learning of the target language (TL) such as overgeneralization and oversimplification. Unlike intra-lingual errors, they occur within the target language. Taylor (1975) has found that once learners have begun to acquire parts of the new system, more and more intra-lingual transfer (generalization within the target language) is manifested. 
Besides, students may commit linguistic mistakes and errors when they miscomprehend what is taught and explained by the teacher. It may even be because of a pattern that was rotely memorized in a drill and improperly contextualized. This type of error can be termed either false concepts or induced errors (Richards, 1971; Stevenson, 1974). For example, two vocabulary items presented contiguously- point at and point out- might in later recall be confused simply because of the contiguity of presentation. Ellis (1994; p. 60) defined induced errors as, "Induced errors occur when learners are led to make errors by the nature of the instruction they have received."

In addition, errors have been classified into different categories and sub categories aiming at making them easier to understand. It is observed that L2 learners commonly commit errors in the usages of parts of speech i.e., nouns, verbs, prepositions, determiners, conjunctions, and adjectives. However, the study focused only on prepositional errors committed by L2 learners.

\section{Methodology}

The researcher employed a Quantitative research methodology in order to find out the ratio of prepositional errors in the writings of Pakistani ESL learners. For this purpose, the researcher selected one of the private schools in Gilgit as research site where ninety three (93) students (40 female and 53 male) were enrolled in class tenth $\left(10^{\text {th }}\right)$. Prior to the sampling process, permission for data collection was sought from the principal of the school through proper channel (appendix, 1). Out of total population, twenty six (26) members were selected through systematic random sampling procedure. During selection phase, thirteen members were selected from each gender using different integers. Moreover, in case of female selection process, a systematic random sampling procedure was employed on the total female strength (40) with $\mathrm{k}(\mathrm{n}) 3$ whereas on the males' population (53) with k (n) 4. After selecting sample members, they were informed and guided as when and where the paper to be conducted.

\subsection{Data Collection Sources}

Two sources were used to gather the information (a) composition test, and (b) participants' assignments.

The first tool employed was a composition test comprised of two sections of 60 minutes. The former section consisted of multiple choice questions (MCQs) based on the selection of appropriate prepositions whereas the latter was comprised of subjective type questions (Appendix, 2). The data collected through the test were later on analyzed through Micro-soft Excel in order to find out the ratio of the prepositional errors in ESL learners' writings.

The second source employed for the required data was the participants' assignments. The researcher collected copies of their assignments and homework to find out deviations in the usages of English prepositions. Besides, the ratio of prepositional errors was also focused.

\section{Data Analysis}

After information gathering, the researcher coded the collected data through assigning different codes and labels in order to process it through Microsoft Excel which may be helpful in identifying the ratio of prepositional error in the participants' writing. Before computerizing the data for the sake of analysis, the researcher coded it manually. Each participant was assigned a number starting from 1 to 26 . During the analysis phase, codes were allotted to the prepositional deviations which were:

\section{1-Direction Preposition Error \\ 2-Place Prepositional Error \\ 3-Time Prepositional Error

After coding the data manually with the aforementioned labels, they were fed into Excel to calculate the means, average and standard deviations in order to find out the results for the questions posed earlier.

Moreover, the errors found in the data were counted in two phases to make the process of analysis transparent and free of errors. Firstly, they were counted separately in each test. Secondly, they were counted collectively in all cases. In addition, all the 26 tests of both male and female were given invented number. For male participants the numbers assigned were starting from M-1 to M-13 whereas for female participants they were started from F-1 to F-13 respectively. Besides, the data were analyzed in tabulated and graphic forms. According to the process following themes were generated.

\subsection{Errors in Place Preposition}

During the analysis process, errors in Place Prepositions were commonly found both in male and female participants' writings. This showed that the participants did not have appropriate knowledge of the use of Place Prepositions. They mostly used incorrect form of prepositions while writing. It may be due to various reasons such 
as L1 interference, lack of English writing competency, due to overgeneralization and false concept hypothesized. However, it is important to be mentioned that the ratio of this type of prepositional errors was higher in the female participants' writing than the males'. Following are some of the examples of place prepositional errors committed by participants.

1. Don't worry; I pass your message onto him.

2. The land we walk through is dirty.

Table 1. Table of Place preposition

\begin{tabular}{llll}
\hline Male participants & & Female participants & \\
\hline Test No. & No. of Errors & Test No. & No. of Errors \\
\hline M-1 & 6 & F-1 & 1 \\
M-2 & 2 & F-2 & 8 \\
M-3 & 3 & F-3 & 6 \\
M-4 & 9 & F-4 & 6 \\
M-5 & 7 & F-5 & 9 \\
M-6 & 6 & F-6 & 5 \\
M-7 & 8 & F-7 & 6 \\
M-8 & 6 & F-8 & 6 \\
M-9 & 6 & F-9 & 3 \\
M-10 & 4 & F-10 & 9 \\
M-11 & 8 & F-11 & 3 \\
M-12 & 4 & F-12 & 5 \\
M-13 & 3 & F-13 & 12 \\
Total & $\mathbf{7 2}$ & Total & $\mathbf{7 9}$ \\
Male errors in \% & $\mathbf{6 5 . 4 5 4}$ & Female errors in $\mathbf{0}$ & $\mathbf{6 8 . 1 0 3}$ \\
\hline
\end{tabular}

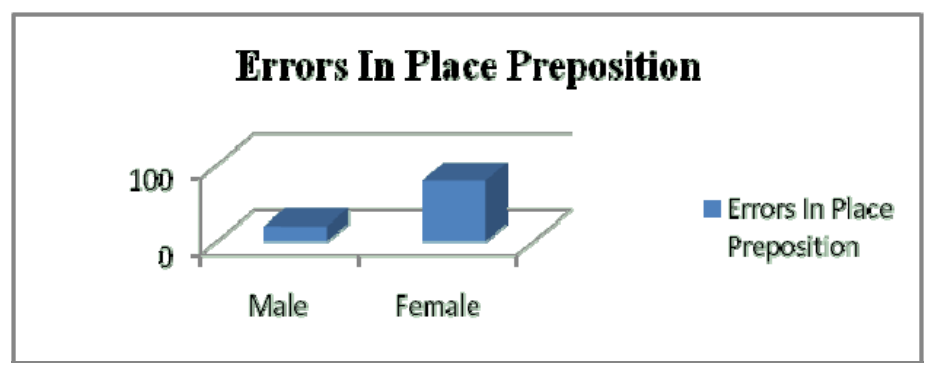

Graph 1

The above table and graph describe the errors committed by sample members in Place Prepositions. Moreover, it is evident in the table that male participants committed 72 errors with a percentage of $65.45 \%$. The highest number of Place Preposition errors found in an individual's writing was nine (9) whereas the lowest number noted was two (2) with average of five and half (5.5) errors per head. On the other hand, the table shows seventy nine (79) place prepositional errors in the writings of female participants with a percentage of $68.10 \%$. In this case, the highest number of Place Preposition errors was twelve (12) whereas one (1) was the lowest number of error found in their writings with average number of six (6) per head.

\subsection{Errors of Direction Preposition}

During the analysis phase of the data, the second highest number of errors found in the participants' writing was the errors in the use of Direction Prepositions. Both male and female students committed second highest number of errors in Direction Prepositions. However, in this type of prepositional errors, males committed more errors than females as shown in the table given below. The most probable reason behind the errors might be the L1 interference through which they could not differentiate between Place and Direction Prepositions. These errors might also be committed either due to the incomplete application of grammatical rules or the overgeneralization of those rules. Following are the examples of errors of Direction Prepositions committed by the participants.

1. People sitting in the sea can send message. (Test No. 10)

2. The post office is situated at my house.

(Test No.12) 
Table 2. Table of direction preposition

\begin{tabular}{llll}
\hline Test No. & No. of Errors & Test No. & No. of Errors \\
\hline M-1 & 5 & F-1 & 1 \\
M-2 & 7 & F-2 & 3 \\
M-3 & 1 & F-3 & 1 \\
M-4 & 1 & F-4 & 0 \\
M-5 & 0 & F-5 & 1 \\
M-6 & 1 & F-6 & 1 \\
M-7 & 1 & F-7 & 0 \\
M-8 & 2 & F-8 & 2 \\
M-9 & 3 & F-9 & 3 \\
M-10 & 0 & F-10 & 2 \\
M-11 & 2 & F-11 & 1 \\
M-12 & 3 & F-12 & 3 \\
M-13 & 0 & F-13 & 2 \\
Total & $\mathbf{2 7}$ & Total & $\mathbf{2 0}$ \\
\% of male errors & $\mathbf{2 3 . 6 8}$ & \% female of errors & $\mathbf{1 6 . 1 2}$ \\
\hline
\end{tabular}

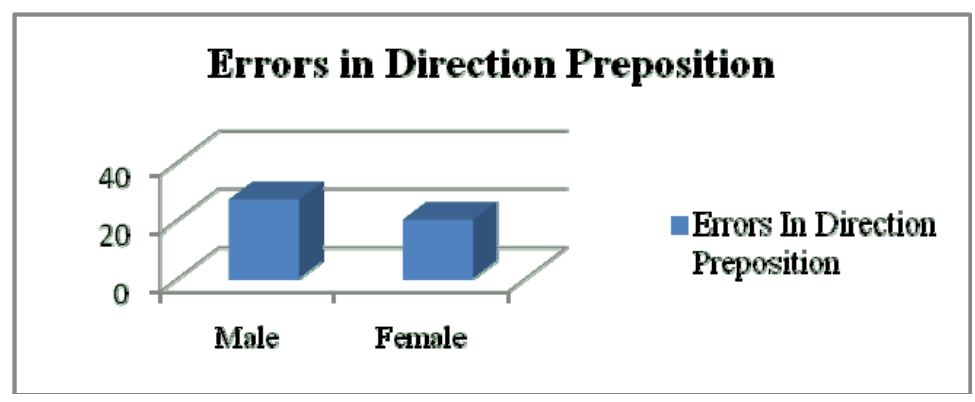

Graph 2

The above table and graph show the Direction Prepositional errors committed by male and female participants. Here, male participants have been shown with twenty seven (27) errors with a percentage of $23.68 \%$. The highest number of errors in Place Preposition made by a single male student was seven whereas the minimum number of errors was one (1). The average of male participants' errors was two (2). On the other hand, female participants committed twenty (20) errors with a percentage of $16.12 \%$. In that case, the highest number of errors was three while the minimum number of errors was one (1) which in total made (2) errors in average.

\subsection{Errors of Time Preposition}

During the analysis phase, another type of prepositional errors was found, called Time Preposition. Participants of both genders committed errors in utilizing Time Prepositions in the writings. However, in that case, the percentage of errors found in their writing was lesser than the above mentioned types of errors. Another striking factor was that male participants committed fewer errors in Time Prepositions as compare to females'. The reason might be the ignorance of the rules restrictions and insufficient knowledge of the use of Time Prepositions. An example of errors in Time Prepositions has been given as under.

I am waiting to my brother.

(Test No. 117) 
Table 3. Table of time preposition errors

\begin{tabular}{llll}
\hline Male & & Female & \\
\hline Test No. & No. of Errors & Test No. & No. of Errors \\
\hline M-1 & 2 & F-1 & 1 \\
M-2 & 2 & F-2 & 1 \\
M-3 & 1 & F-3 & 1 \\
M-4 & 1 & F-4 & 1 \\
M-5 & 0 & F-5 & 2 \\
M-6 & 0 & F-6 & 2 \\
M-7 & 0 & F-7 & 1 \\
M-8 & 1 & F-8 & 1 \\
M-9 & 1 & F-9 & 3 \\
M-10 & 0 & F-10 & 1 \\
M-11 & 2 & F-11 & 1 \\
M-12 & 1 & F-12 & 2 \\
M-13 & 0 & F-13 & $\mathbf{1 7}$ \\
Total & $\mathbf{1 1}$ & Total & 14.65 \\
\% of errors & 10 & \%of errors & \\
\hline
\end{tabular}

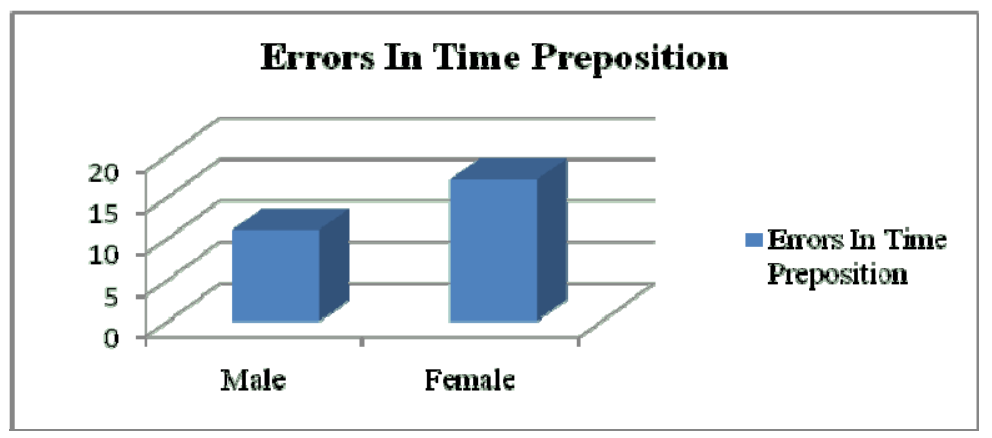

Graph 3

The above table and graph show the errors in the use of Time Prepositions committed by male and female students. Here, male students have been shown with eleven (11) errors with a percentage of $10 \%$ whereas female students have committed seventeen (17) errors with a percentage of $14.65 \%$. The highest number of errors in Place Preposition made by a single male student was two (2) with one (1) average while zero (0) was the minimum number of errors. On other hand, the table highlights three (3) as a highest number of errors with two (2) average number while one (1) was the minimum number of errors found in the female participants' writing.

\subsection{Errors in Both Genders' Writing}

The result of the study testified the hypothesis that male students committed lesser prepositional errors as compare to female students. The following table shows the errors committed by both genders. The total errors committed by the participants of both genders were two hundred and twenty six prepositional errors in which male students committed seventy two (72) Place Prepositional errors, Twenty Seven (27) Direction Prepositional errors, and eleven (11) Time Prepositional errors with a percentage of $48.67 \%$, whereas female students comparatively committed more errors with one hundred and sixteen (116) errors in which seventy nine (79) errors were of Place Prepositional errors, twenty (20) were Direction Prepositional errors and seventeen (17) errors were of Time Prepositions with a total percentage of $51.32 \%$.

Table 4. Errors committed by both genders

\begin{tabular}{lll}
\hline Category of errors & Male & Female \\
\hline Place preposition & 72 & 79 \\
Directional preposition & 27 & 20 \\
Time preposition & 11 & 17 \\
Total errors & $\mathbf{1 1 0}$ & $\mathbf{1 1 6}$ \\
\%wrt total errors & $\mathbf{4 8 . 6 7}$ & $\mathbf{5 1 . 3 2}$ \\
\hline
\end{tabular}




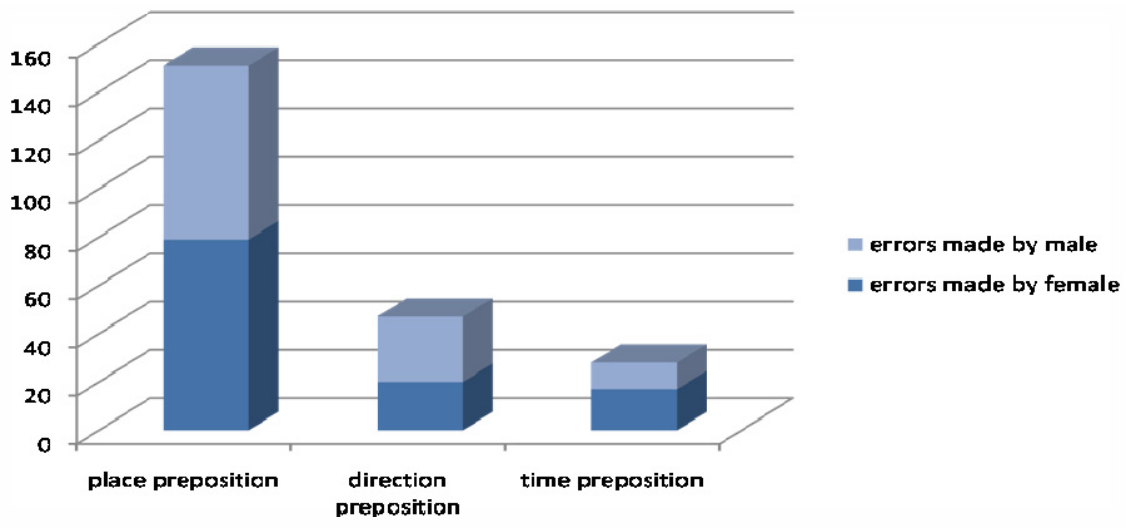

Graph 4

This graph shows the errors in preposition made by both genders. Horizontally, the graph shows number of errors committed by male and female students (0-160) while vertically it shows types of Prepositional errors committed by them. Besides, it also highlights the percentage of errors committed by both genders.

\section{Discussion}

\subsection{Prepositional Errors Ratio}

In this study, the prepositional errors ratio is different in ESL learners. According to three types of preposition, both male and female student's errors ratio is different. Male committed 110 errors in uses of Preposition with the percentage of $48.67 \%$ and female committed 116 errors with the percentage of $51.32 \%$.

\subsection{Error Ratio of Male Is Higher than Female Students}

From data, we found error ratio of female student was higher than males. According to the result, the first hypothesis (see in chapter 1) was testified as a null hypothesis. Furthermore, it was found out that female students committed more prepositional errors in writing than males particularly in cases of 'place and time Prepositions' whereas in case of Direction Preposition, male committed more errors as compared to female students. In overall result for the mistakes and errors, the proposition of the female is larger than the male students. The findings of this research are not in line with other researches of the same area like Strong (2009) in which he found that female learners used more enriched language than their counter parts. Saeed (2012) also found that female learners performed well in the analysis of learning Past tense as compare to male students though the difference was very significant.

\subsection{Most Problematic Preposition in Usage}

When we analyzed the data, it seemed that some prepositions were most problematic in usage in L2 writings and drafting. During the data collection and analysis processes, we observed that Place and Time Prepositions were the most problematic for the students to use. Ahmed (2011) found the same findings in his study on prepositional error analysis of secondary school students studying English. He found that students faced most difficulty in the use of Time preposition. It was also noticed that students committed errors in the use of "on, from, in, at". So, it can be said that students have no appropriate knowledge of their Preposition or a definite rule to draw line among them, they mostly used incorrect placement of the propositions while writing. Errors occur due to false concept of hypothesis

\section{Conclusion}

After the analysis of the data it was found that the female students committed more errors in the use of preposition as compare to male students. Male students committed total 110 errors while female students committed total 116 errors. It clearly shows the low level of proficiency of female students in L2 writing.

The students of both gender i.e. male and female committed highest number of errors in the use of Place preposition. Male students committed 72 errors out of 110 errors in the use of Place Preposition with a percentage of $65.454 \%$ with respect to errors made by female students while female students committed 79 errors out of 116 errors in the use of Place Preposition with a percentage of $68.103 \%$. These highest percentages show that the students on the whole are unaware of the use of Place Preposition. Sometimes they used Direction Preposition instead of Place Preposition and the other time used unnecessary preposition. Thus they committed more errors in 
Place Preposition.

As far as the use of Direction Preposition is concerned, students of the both gender committed second highest percentage of errors in its use. Male students committed 27 errors with a percentage of $123.68 \%$ while female students committed 20 errors with a percentage of $61.12 \%$. Most of students used Place Preposition in the place of Direction Preposition. It reflects that students have least attention towards the proper usage of Place Preposition.

Male students committed only 11 errors with a percentage of $11.15 \%$ in the use of Time preposition while female students committed only 15 errors with a percentage of 12.09. It seemed that they were quite unaware of its right use.

As far as the sources of errors are concerned, it was observed that the errors were generally caused as described by many linguists i.e. L1 interference, overgeneralization, incomplete application of rules and false concept hypothesis.

After a reflective thinking on the difference of errors between male and female students as female students committed more errors as compare to male students on the bases of different tools, one can state that males are more conscious about their writing.

\section{References}

Ahmed, N. (2011). Error Analysis: Learning Articles and Prepositions among Secondary School Students in Pakistan. Interdisciplinary Journal of Contemporary Research in Business, 2(12), 385-390.

Brown, H. D. (2000). Principles of Language Learning and Teaching (4th ed.). New York: Longman.

Corder, S. P. (2000). Error Analysis. London: Longmans Publisher.

Ellis, R. (1994). The Study of Second Language Acquisition. Oxford: Oxford University Press.

Gardner, R. (1985). Social Psychology and Second Language Writing: The Role of Attitude and Motivation. London: Edward Arnold.

Griffiths, R., \& Ronald, S. (1992). Disembedded figures in the land escope: A reappraisal of L2 research on field

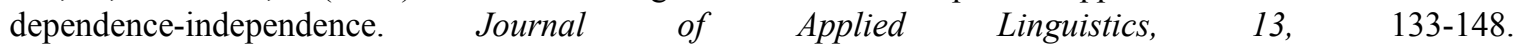
http://dx.doi.org/10.1093/applin/13.2.133

Hendrickson, J. M. (1980). Error Correction in Foreign Language Teaching: Recent theory, research and practice. In K. Croft (Ed.), Reading on English as a Second Language (2nd ed.). Cambridge, MA: Winthrop Publisher.

Kachru, B. B. (1992). World Englishes: approaches, issues and resources. Language Teaching, 25, 1-14. http://dx.doi.org/10.1017/S0261444800006583

Krashen, S. (1982). Principles and practice in Second Language Acquisition. Oxford: Pergamon.

Lakoff, R. (1975). Language and Women's Place. New York: Harper Colophen.

Larsen-Freeman, D., \& Long, M. H. (1991). An introduction to second language research. London: Longman.

Long, M. H. (1977). Teacher feedback on learner error: Mapping cognition. In H. D. Brown et al. (Eds.), Teaching and Learning English as a Second Language: Trends in Research and Practice. On TESOL 77.

Rehman, Z. (2008). Ilmi English Simple Grammar and Composition.

Rehman. Z. (2006). Ilmi English Simple Grammar and Composition.

Richards, J. (1974). Error Analysis. London: Longman.

Saeed, A. (2012). Analysis of Past Tense in Perspective of Gender: A Case Study in Gilgit-Baltistan, Pakistan. Balochistan Review, XXVII(2).

Saeed, A. S. (1998). Exploring the world of English.

Silva, T. (1993). Towards an understanding of the distinct nature of L2 writing: The ESL research and its implications. TESOL Quarterly, 27, 657-667.

Stevenson, B. (1974). Induced Errors. In J. Schumann \& N. Stenson (Eds.), New Frontiers in Second Language Learning. Rawley, Mass: Newbury House.

Strong, J. et al. (2009). Pain Language and gender differences when describing a past pain event. PAIN, 145 , 86-95. 


\section{Copyrights}

Copyright for this article is retained by the author(s), with first publication rights granted to the journal.

This is an open-access article distributed under the terms and conditions of the Creative Commons Attribution license (http://creativecommons.org/licenses/by/3.0/). 